\title{
CAPÍTULO 13: ATIVIDADES DE PIBIC DURANTE A PANDEMIA: UMA POSSIBILIDADE DE SE REINVENTAR
}

\section{CAPÍTULO 13: ACTIVIDADES DE PIBIC DURANTE LA PANDEMIA: UNA POSIBILIDAD DE SE REINVENTAR}

\section{CHAPTER 13: ACTIVITIES OF PIBIC DURING PANDEMIC: A POSSIBILTY TO REINVENT MYSELF}

Guilherme de Siqueira Freitas Pontes ${ }^{1}$; Kleber Danylo Mendes da Silva ${ }^{2}$; Simone de Paula Silva ${ }^{3}$; Erick Viana da Silva ${ }^{4}$

DOI : https://doi.org/10.31692/978-65-88970-03-4.193-197

\section{INTRODUÇÃO}

Este trabalho acadêmico pretende expor o diferencial de como se pôde aproveitar um momento conturbado de pandemia visando o desenvolvimento pessoal, profissional e, principalmente acadêmico. Serão relatadas as atividades desenvolvidas e quais efeitos destas na vida dos estudantes autores, uma vez que, sob orientação da docente, foi-lhes possibilitado abrir os horizontes e se propor a ações efetivas na sociedade.

Tais ações acadêmicas ocorreram entre os meses de março e abril, maio e junho de 2020, meses de maiores restrições sociais e pleno isolamento social, viabilizaram atividades remotas as quais trouxe contato com conceitos de ética, empreendedorismo, além de compreender o contexto socioeconômico do momento vivido.

\section{RELATO DE EXPERIÊNCIA}

No mês de março, após o início da pandemia, foi verificado que não seria possível entregar as frequências mensais de forma presencial e nem realizar atividades no campus Recife. Desta forma, a docente propôs aos discentes do curso uma redação a respeito dos efeitos econômicos do momento pandêmico.

Foi possível perceber que, de início, muitas empresas necessitaram fechar suas portas por tempo determinado, levando a quedas de rendimentos (BBC, 2020). Outras, porém, com soluções digitais, tiveram crescimento, tal como a Netflix (BBC, 2020).

Já no mês de abril, percebendo-se ainda a possibilidade de maior durabilidade da epidemia global (FORATO, 2020), foram requeridas algumas atividades, por exemplo,

\footnotetext{
${ }^{1}$ Gestão de Turismo, Instituto Federal de Pernambuco, guilhermesfpontes@gmail.com

${ }^{2}$ Análise de Desenvolvimento e Sistemas, Instituto Federal de Pernambuco, kdms@discente.ifpe.edu.br

${ }^{3}$ Mestra em Gestão Ambiental, Instituto Federal de Pernambuco, simonedypaula@gmail.com

${ }^{4}$ Mestre em Administração, Instituto Federal de Pernambuco, erick.viana@recife.ifpe.edu.br
} 
assistir uma palestra em plataforma conhecida de transmissão de vídeo com conhecido empreendedor brasileiro, conforme o print abaixo.

Figura 1: Print sobre Atividades no Pibic

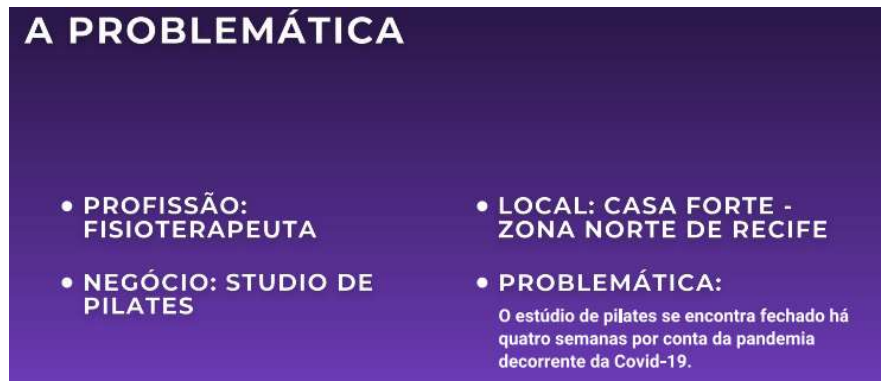

Fonte: Própria (2020)

Outra atividade do mês em questão foi propor possíveis soluções para alguns grupos profissionais, entre os quais se destacam: ramo de alimentação em frente ao Instituto Federal de Pernambuco, quando buscou-se contato com os mesmos para entender se tinham contato com aplicativos de entrega de alimentos para poderem trabalhar por delivery. Vale ressaltar que esta ferramenta tornou-se aliada de muitos restaurantes para sair da crise (SILVA, LUIS, MENESES, 2020). Outros dois pequenos negócios foram um salão de beleza e um estúdio de fisioterapia, no qual foi possível perceber que, mesmo em negócios distintisos, possuir interação com redes sociais é intrínseco ao desenvolvimento e contato próximo aos clientes antigos e possível forma de adquirir novos clientes (CASTGROUP, 2020). Conforme explicado, algumas figuras a seguir ilustram o exposto.

Por fim, em maio de 2020, atividades a respeito de conceito de ética foram implementadas, no ambiente de trabalho e nas redes sociais. Com vídeos relacionados a este aspecto, foram estudados tais temas, concluindo que ética "é o conjunto de princípios e valores que usamos para decidir a nossa conduta social". (CORTELLA, 2020). De acordo com as imagens a seguir, pode-se ter uma ideia das atividades desenvolvidas. Outras atividades (figuras 2, 3 e 4) requeridas foram sobre uma análise do papel das lives entretenimento, uma vez que possibilitaram artistas e fãs continuarem conectados virtualmente (KARAM, 2020), bem como possíveis retomadas da economia, de acordo com estudos em portais virtuais, partindo de uma economia com pouca intervenção estatal até uma economia puramente interventora (CARRANÇA, 2020) . 
Figura 2: Exemplo de lives

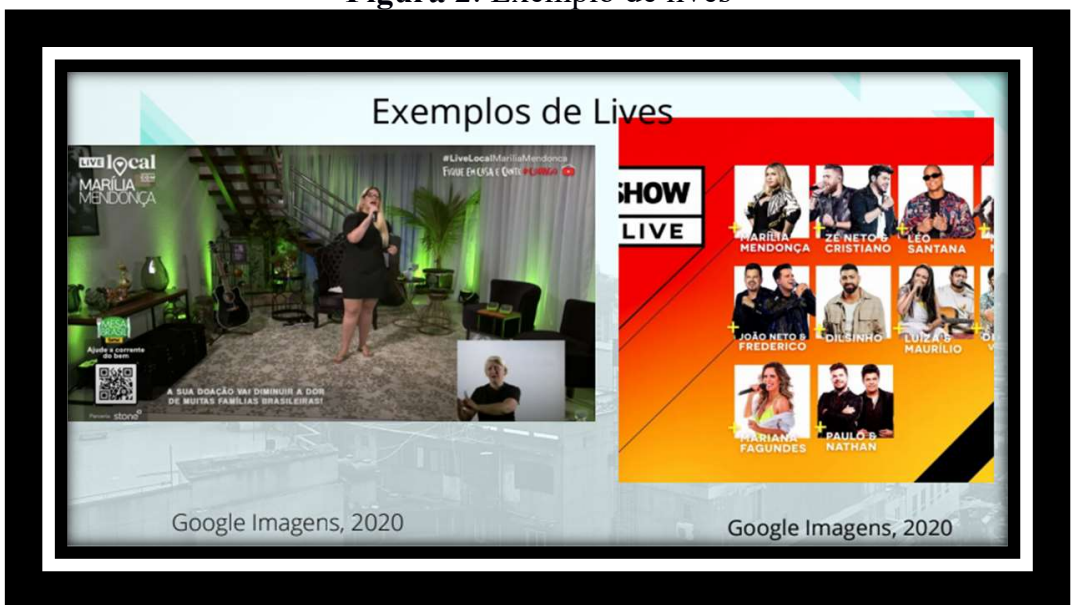

Fonte: Própria (2020)

Figura 3: Ética nas redes sociais

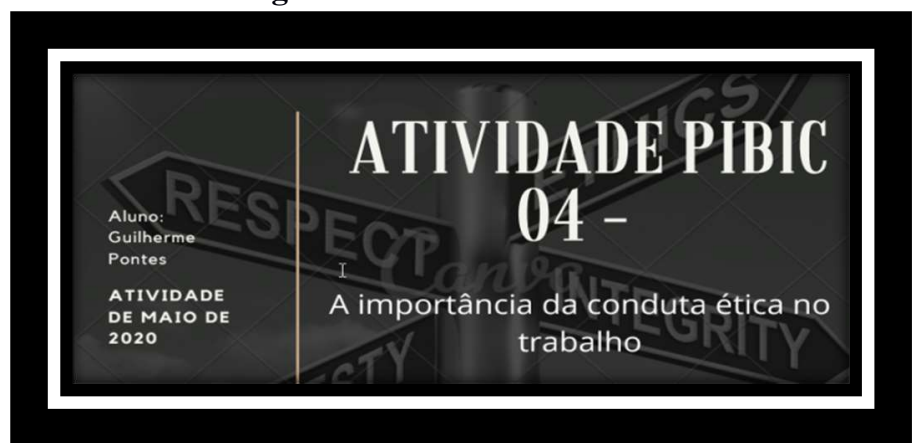

Fonte: Própria (2020)

Imagem 4: Reinvenção do consumo

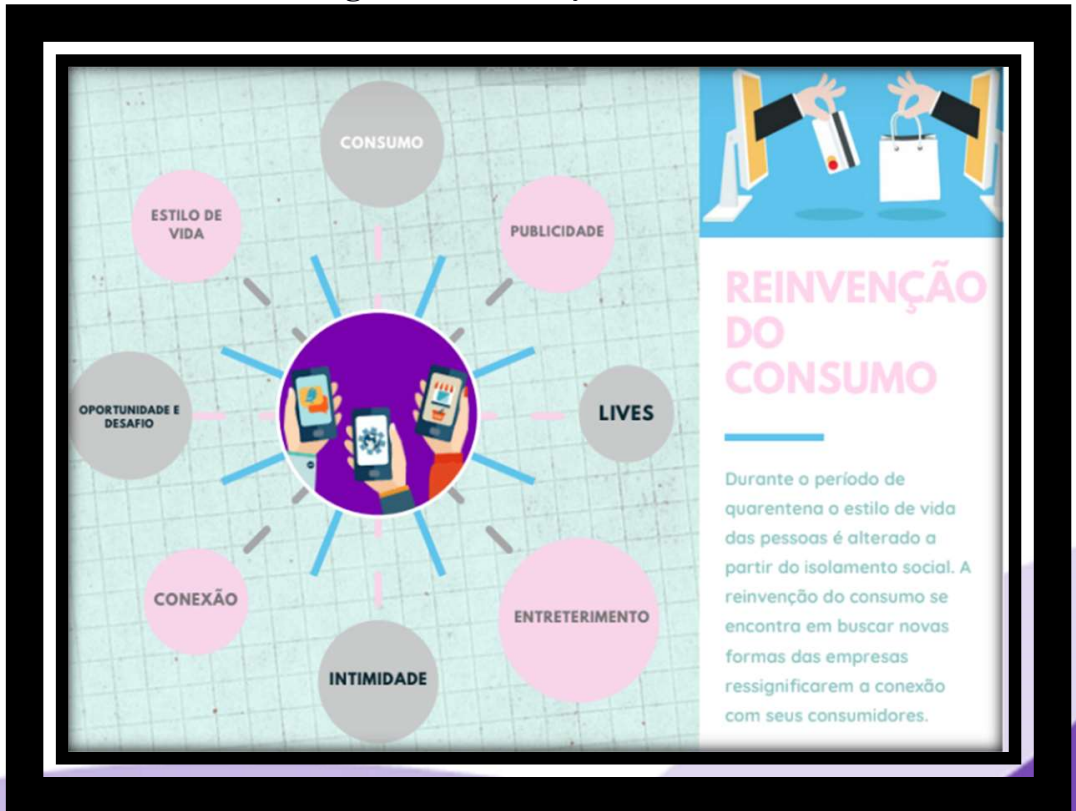

Fonte: Própria (2020). 
Além destas apresentações com ferramentas digitais, os estudantes participaram de hackathons (Guizardi et al (2018), como o HackingHelp Rio, em maio de 2020 (ANPROTEC, 2020) e o Startup Way Federais (IFPE, 2020), em junho. O intuito das maratonas foi idealizar soluções para o momento pós-pandêmico.

\section{CONCLUSÕES}

Conforme descrito ao decorrer do texto, é possível seguir realizando atividades acadêmicas e expandindo o saber com atividades de pesquisa e extensão, mesmo que de forma remota. Compreender as dificuldades exigidas do momento não se justifica a apenas se omitir e não continuar produzindo, mas sim uma forma importante de se desafiar e superar barreiras, visando à solução ou mínima compreensão das dificuldades da situação em questão.

\section{REFERÊNCIAS}

BBC. Coronavírus: como a queda da bolsa afeta a 'economia real? Disponível em: https://g1.globo.com/economia/noticia/2020/03/13/coronavirus-como-a-queda-da-bolsa-afetaa-economia-real.ghtml Acesso em: 31 de março de 2020

BBC. Coronavírus: quem está ganhando dinheiro com a epidemia? Disponível em: https://g1.globo.com/economia/noticia/2020/03/05/coronavirus-quem-esta-ganhandodinheiro-com-a-epidemia.ghtml Acesso em: 31 de março de 2020.

CARRANÇA, T. Cinco propostas para retomar economia após coronavírus. Disponível em: $\quad$ https://economia.uol.com.br/noticias/bbc/2020/04/27/5-propostas-para-retomareconomia-apos-coronavirus.htm Acesso em: 10 de setembro de 2020.

CASTGROUP. 6 tecnologias para aumentar o resultado da área de vendas. Disponível em: https://www.castgroup.com.br/blog/6-tecnologias-para-aumentar-os-resultados-da-areade-vendas/ Acesso em: 10 de setembro de 2020.

CORTELLA, M. S. Ética é sempre coletiva. Disponível em: http://www.mscortella.com.br/artigo-cortella-etica-moral-valores-principios-6a Acesso em: 10 de setembro de 2020.

FORATO, F. Quanto tempo pode durar a pandemia da COVID-19. Disponível https://canaltech.com.br/saude/quanto-tempo-pode-durar-a-pandemia-da-covid-19-162509/ Acesso em: 08 de setembro de 2020.

GUIZARDI, F.L; SANTOS, K.G; LEMOS, A.S.P; SEVERO, F.M.D . Maratonas hackers no Brasil com desafios no campo da Saúde. São Paulo: Interface (Botucatu), 2018.

IFPE. IFPE promove Startup Way para desafios pós Covid-19. Disponível em: https://portal.ifpe.edu.br/noticias/sebrae-universidades-e-institutos-federais-de-pernambucopromovem-startup-way-para-desafios-apos-covid-19. Acesso em 09 de setembro de 2020. 
KARAM, K. "Lives": as novas conexões de um consumidor que não será mais o mesmo. Disponível em: https://economia.uol.com.br/colunas/2020/04/22/lives-as-novas-conexoes-deum-consumidor-que-nao-seravmaisvo-mesmo.htm Acesso em: 10 de setembro de 2020.

CASTGROUP. 6 tecnologias para aumentar o resultado da área de vendas. Disponível em: https://www.castgroup.com.br/blog/6-tecnologias-para-aumentar-os-resultados-da-areade-vendas/ Acesso em: 10 de setembro de 2020. 